0
1
0

Ice Strength as a Func tion of Hydrostatic Pressure and Temperature

Ana toly M. Fish and Yuri K. Za retsky

October 1997

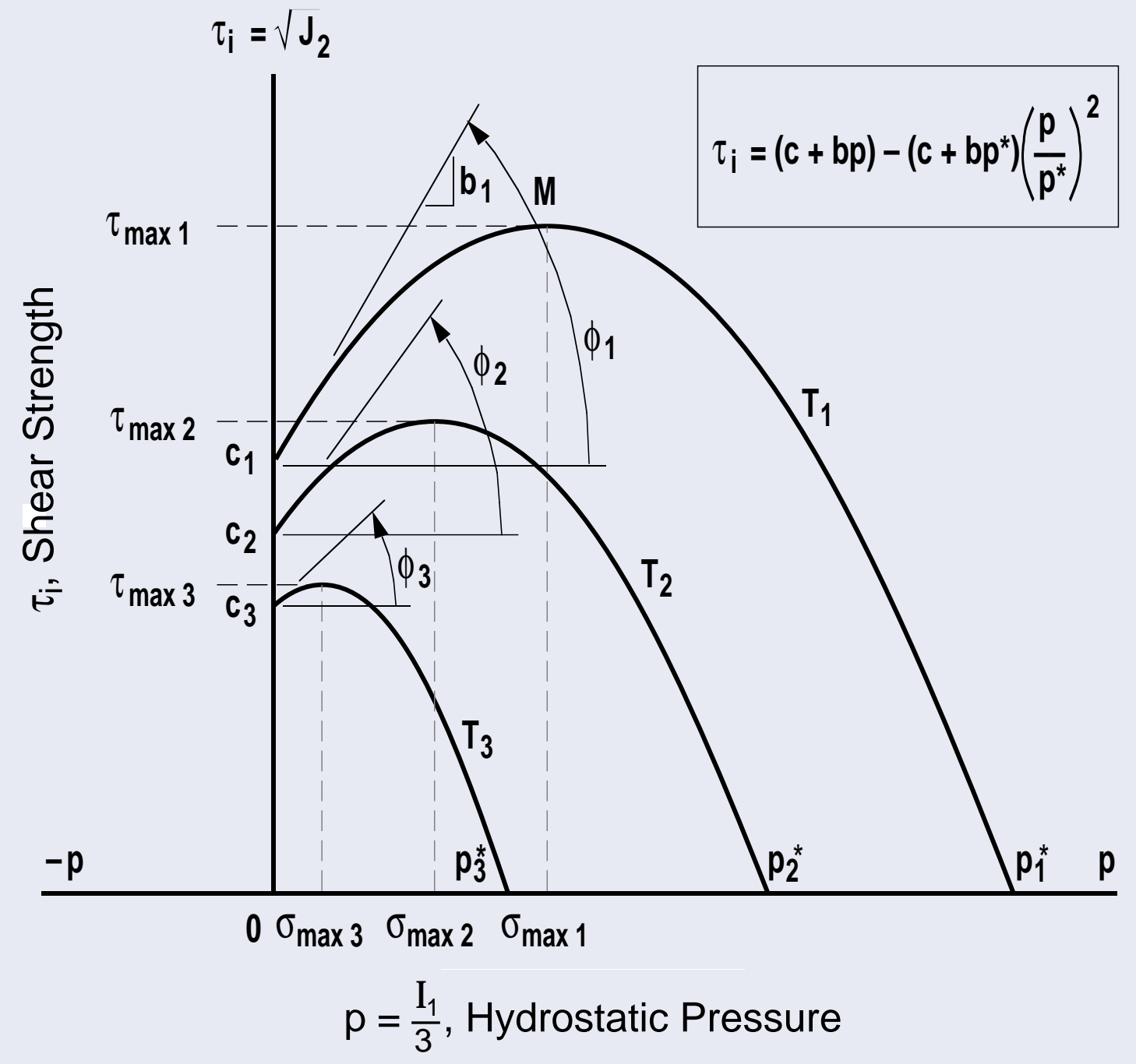


Abstract: A temperature model has been developed that describes the ice strength in a multiaxial stress state over a wide spectrum of negative temperatures. The model takes into account the anomalous behavior of ice under high hydrostatic pressure, when its strength reaches a maximum, and then gradually decreases with the pressure increase. It has been shown that strength of ice under high hydrostatic pressure is described by a parabolic yield criterion with only three fundamental parameters, ice cohesion, internal friction angle, and ice melting pressure, which all have a definite physical meaning and are functions of temperature. The model has been verified using test data on the strength of iceberg ice and laboratory-made polycrystalline freshwater ice under triaxial compression at strain rates between $10^{-3}$ and $10^{-5} \mathrm{~s}^{-1}$ over the temperature range between $-1^{\circ}$ and $-40^{\circ} \mathrm{C}$.

Cover: Strength envelopes of ice at various temperatures: $c, \phi, p^{*}$, and $T$ are the ice cohesion, friction angle, ice melting pressure, and absolute temperature, respectively.

\section{How to get copies of CRREL technical publications:}

Department of Defense personnel and contractors may order reports through the Defense Technical Information Center: DTIC-BR SUITE 0944

8725 J OHN J KINGMAN RD

FT BELVOIR VA 22060-6218

Telephone $\quad 18002253842$

E-mail help@dtic.mil msorders@dtic.mil

WwW http://www.dtic.dla.mil/

All others may order reports through the National Technical Information Service: NTIS

5285 PORT ROYAL RD

SPRINGFIELD VA 22161

Telephone 17034874650

17034874639 (TDD for the hearing-impaired)

E-mail_orders@ntis.fedworld.gov

WWW http://www.fedworld.gov/ntis/ntishome.html

A complete list of all CRREL technical publications is available from

USACRREL (CECRL-LP)

72 LYME RD

HANOVER NH 03755-1290

Telephone 16036464338

E-mail_techpubs@crrel.usace.army.mil

For information on all aspects of the Cold Regions Research and Engineering Laboratory, visit our World Wide Web site: http://www.crrel.usace.army.mil 


\section{CRREL Report 97-6}

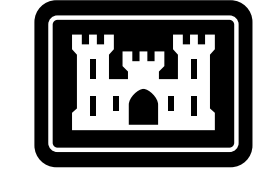

US Army Corps of Engineers $\odot$

Cold Regions Research \& Engineering Laboratory

\section{Ice Strength as a \\ Function of Hydrostatic Pressure and Temperature}

Ana toly M. Fish and Yuri K. Za retsky

October 1997 


\section{PREFACE}

This report was prepared by Dr. Anatoly M. Fish, Research Civil Engineer, of the Civil Engineering Research Division, Research and Engineering Directorate, U.S. Army Cold Regions Research and Engineering Laboratory; and Dr. Yuri K.Zaretsky, Director, Institute of Geomechanics and Hydrostructures, Moscow, Russia. Funding of this research was provided by DA Project 4A762784AT42, Cold Regions Engineering Technology, Work Package 201, Conventional Facilities in Cold Regions, Work Unit CA-D13, Geotechnical Structures in Cold Regions.

The authors extend their appreciation to Dr. Devinder Sodhi, Dr. Patrick Black, and Dr. Stephen Ketcham of CRREL for technical review of this report and their valuable comments.

The contents of this report are not to be used for advertising or promotional purposes. Citation of brand names does not constitute an official endorsement or approval of the use of such commercial products. 


\section{CONTENTS}

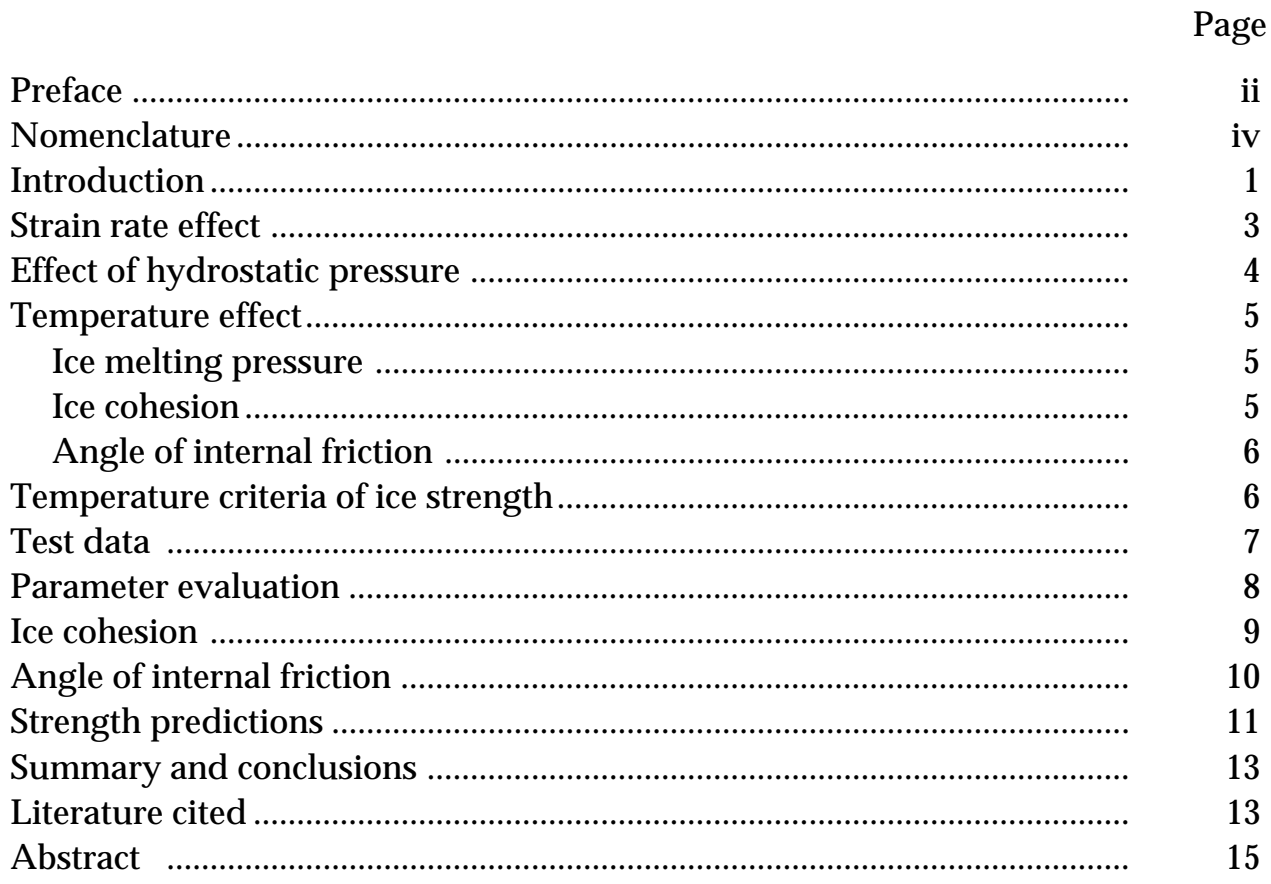

\section{ILLUSTRATIONS}

Figure

1. Strength envelopes of ice at various temperatures .............................. 2

2. Temperature diagrams of the strength parameters of ice .................. 6

3 Strength test data of ice under triaxial compression ..........................

4. Temperature dependencies of the strength parameters of ice ........... 8

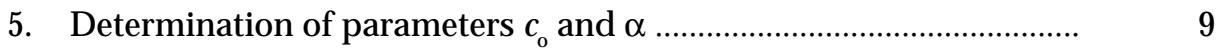

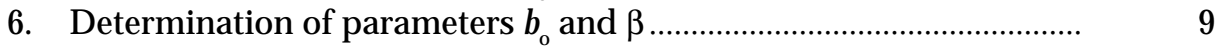

7. Angle of internal friction of ice as a function of temperature ........... $\quad 10$

8. Strength of ice as a function of temperature and confining pressure

9. Predicted and test magnitudes of ice strength under triaxial compression at various temperatures ............................................ 12

10. Strength of ice in the range of high hydrostatic pressures at

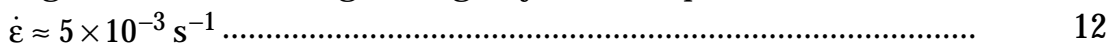

\section{TABLES}

Table

1. Strength parameters of ice at various temperatures ............................ 8

2. Strength predictions of Labrador iceberg ice ..................................... 11 


\section{NOMENCLATURE}

A ice melting coefficient

$B \quad$ flow equation parameter

$b=\tan \phi$, internal friction parameter

$b_{0} \quad$ internal friction parameter at freezing

$b_{1} \quad$ component of the internal friction parameter at $T<T_{\mathrm{m}}$

$\tilde{C} \quad$ material constant

c ice cohesion

$c_{0} \quad$ ice cohesion at freezing

$c_{1} \quad$ component of ice cohesion at $T<T_{\mathrm{m}}$

d grain diameter

E activation energy

h Planck's constant

$h_{2} \quad$ negative hydrostatic pressure at which the ice shear strength equals zero

$I_{1} \quad$ first invariant of the stress tensor

$J_{2}$ second invariant of the stress deviator

$k \quad$ Boltzmann's constant

$L_{\mathrm{m}} \quad$ specific heat of melting of the unit mass

$n \quad$ strain hardening parameter

$p \quad$ hydrostatic pressure

$p^{*} \quad$ ice melting pressure

$R \quad$ gas constant

$S_{\ell}, S_{\mathrm{s}} \quad$ unit mass entropy of the liquid and solid state, respectively

$T \quad$ absolute temperature

$T_{m} \quad$ ice melting temperature

$t_{\mathrm{o}} \quad$ failure time at strain rate, $\dot{\gamma}_{\mathrm{i}}=\dot{\gamma}_{\mathrm{io}}$

$V_{\ell}, V_{\mathrm{s}} \quad$ unit mass volume of the material in the liquid and solid state, respectively

$\alpha \quad$ empirical parameter of the cohesion

$\beta, \beta_{1} \quad$ parameters of the internal friction angle

$\dot{\gamma}_{\mathrm{i}} \quad$ octahedral strain rate

$\dot{\gamma}_{\text {io }} \quad$ octahedral (referenced) strain rate

$\gamma_{\mathrm{i}} \quad$ octahedral strain

$\gamma_{\text {io }} \quad$ octahedral (referenced) strain

$\varepsilon \quad$ axial strain

$\varepsilon_{\mathrm{o}} \quad$ axial (referenced) strain

$\dot{\varepsilon}=\dot{\varepsilon}_{1} \quad$ axial strain rate

$\dot{\varepsilon}_{\mathrm{O}} \quad$ axial strain rate (referenced)

$\eta \quad$ viscosity coefficient

$\theta \quad$ temperature, Celsius

$\sigma_{\max } \quad$ hydrostatic pressure at which the shear strength of ice reaches a maximum value

$\sigma_{1,2,3} \quad$ principal stress

$\tau_{\mathrm{i}} \quad$ octahedral shear stress (strength)

$\tau_{\max } \quad$ maximum shear stress (strength)

$\phi \quad$ internal friction angle

$\phi_{1} \quad$ component of internal friction angle at $T<T_{\mathrm{m}}$

$\phi_{0} \quad$ internal friction angle at freezing

$\omega$ parameter of the internal friction angle at $T<T_{\mathrm{m}}$ 


\title{
Ice Strength as a Function of Hydrostatic Pressure and Temperature
}

\author{
ANATOLY M. FISH AND YURI K. ZARETSKY
}

\section{INTRODUCTION}

Studies of ice strength in the second half of this century have attracted efforts of a number of researchers. Their attention has been focused on investigation of ice strength as a function of the strain rate, temperature, grain size, and other factors mainly in simple stress-strain state, uniaxial compression. During the last two decades, however, the attention of researchers was shifted to investigation of the mechanical behavior of ice, particularly the strength of ice, in a complex stressstrain state such as triaxial compression.

In a general case, strength of ice in a multiaxial stress state, when other conditions (the type of ice, its structure, the grain size, etc.) are equal, can be presented as

$$
\tau_{\mathrm{i}}^{*}=\tau_{\mathrm{i}}^{*}\left(\dot{\gamma}_{\mathrm{i}}, p, T\right)
$$

where $\tau_{\mathrm{i}}^{*}=\tau_{\mathrm{i}}=\sqrt{J_{2}}=$ octahedral (peak) shear stress

$J_{2}=$ second invariant of the stress deviator

$\dot{\gamma}_{\mathrm{i}}=$ octahedral constant shear strain rate

$p=I_{1} / 3=$ hydrostatic pressure

$I_{1}=$ first invariant of the stress tensor

$T=$ ice temperature, $\mathrm{K}$.

The first studies of the effect of low confining pressure on creep strength of ice under triaxial $\left(\sigma_{2}=\sigma_{3}\right)$ compression were carried out by Sayles (1974). The studies showed that the ice strength is a nonlinear function of the confining pressure. More detailed investigations of the effect of the strain rate and high confining pressures on the ice strength under triaxial $\left(\sigma_{2}=\sigma_{3}\right)$ compression were

* Denotes failure stress performed by Jones $(1978,1982)$. The studies, carried out over a wide range of constant strain rates and confining pressures, revealed the anomalous behavior of ice when its shear strength (at a certain magnitude of confining pressure) reaches a maximum attributable to melting of ice, and then gradually decreases with the pressure increase. Jones showed that the ice strength is a nonlinear (power) function of the axial (constant) strain rate (see eq 1c below). Further experimental studies with various types of ice revealed effects of temperature, salinity, structure, and other factors on the ice strength (Hausler 1983, Nadreau and Michel 1986, Richter-Menge et al. 1986, Timco and Frederking 1986, Nadreau et al. 1991, Rist and Murrell 1994, Gagnon and Gammon 1995, Weiss and Schulson 1995 and others).

At the same time mathematical models were also developed. Thus, Reinicke and Ralston (1977) and Hausler (1986) applied a parabolic equation of Smith (1974), developed originally for rocks, to describe the strength dependency of ice upon the hydrostatic pressure (in our notation):

$$
\tau_{\mathrm{i}}^{*}=\tau_{\mathrm{i}}^{*}(p) .
$$

The absolute magnitudes and the physical meaning of the parameters in the Smith equation have not been defined.

Nadreau proposed a model (Nadreau and Michel 1986) that described the nonlinear dependency of ice strength on confining pressure $\left(\sigma_{2}=\right.$ $\sigma_{3}$ ) by means of a third-order polynominal function with four phenomenological parameters, to be determined from a series of triaxial tests of ice at different strain rates, and the principal parameter-the ice melting pressure $p^{*}$. This pressure was suggested to be determined either from the ice state diagram or to be calculated by an empirical equation. 
In the model of Fish $(1991,1992,1993)$ the relationship

$$
\tau_{\mathrm{i}}^{*}=\tau_{\mathrm{i}}^{*}\left(p, \dot{\gamma}_{\mathrm{i}}\right) ; \quad T=\text { Const }
$$

was described by a product of two functions: 1) a parabolic function-extended by Fish (1991) the Drucker-Prager yield criterion, and 2) a normalized (dimensionless) power function of the strain rate. The yield criterion describes the strength dependency of ice on the hydrostatic pressure by means of three parameters: the cohesion $c$, the friction angle $\phi$ and the magnitude of the hydrostatic pressure $\sigma_{\max }$ at which the shear strength of ice reaches a maximum $\tau_{\max }$, related to the ice melting pressure $p^{*}$ (Fig. 1). The model described Jones' (1982) test data well. It was shown that the ice cohesion and the friction angle are functions of the strain rate.

The temperature effect on ice strength under triaxial compression was studied by Rist and Murrell (1994) and Gagnon and Gammon (1995) using the Arrhenius-type (Norton-Glen) equation,

$$
\dot{\varepsilon}=B \exp (-E / R T) \tau_{\mathrm{i}}^{\mathrm{n}}
$$

where $\dot{\varepsilon}=$ axial (constant) strain rate

$B=$ empirical parameter

$E=$ activation energy

$R=$ universal gas constant

$T=$ absolute temperature, $\mathrm{K}$

$n \approx 4=$ strain hardening parameter (Jones 1982), in which the temperature variations of the ice strength are characterized by only one parameter-the activation energy. The apparent activation energy magnitudes were found as $E=69 \mathrm{~kJ}$ $\mathrm{mol}^{-1}$ in the temperature range between $-20^{\circ}$ and $-40^{\circ} \mathrm{C}$ (Rist and Murrell 1994), and $E=101 \mathrm{~kJ}$ $\mathrm{mol}^{-1}$ in the temperature range between $-1^{\circ}$ and $-16^{\circ} \mathrm{C}$ (Gagnon and Gammon 1995). The higher activation energy magnitudes were explained by grain-boundary softening associated with the presence of liquid on grain boundaries.

Equation 1c implies that the nonlinear (with regard to stress) viscosity coefficient of ice,

$$
\eta(T)=1 / B \exp (E / R T),
$$

is independent of the hydrostatic pressure. In other words, ice is assumed to be incompressible.

It has been shown earlier (Fish 1991) that the ice strength in a multiaxial stress state is characterized by two or more temperature-dependent parameters that can affect the magnitude of the apparent activation energy: the ice cohesion, the friction angle, and the hydrostatic pressure. So the predicted values of the ice strength, calculated by eq 1c, may deviate considerably from those obtained in the tests.

A mathematical model (Zaretsky and Fish 1996a, 1996b) takes into account the effect of all three variables in eq 1 . The ice strength is described by three parameters: the ice cohesion, friction angle and ice melting pressure. The ice cohesion and the friction parameter are assumed to be

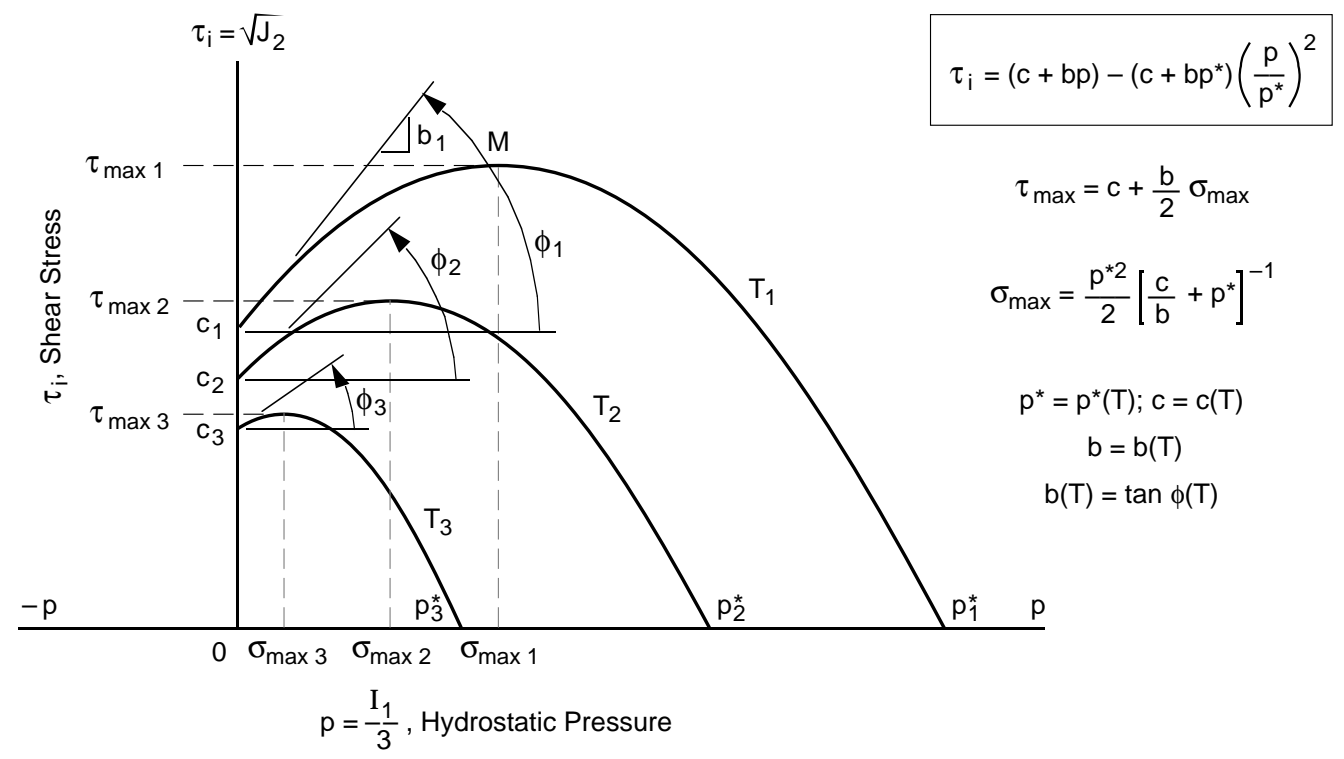

Figure 1. Strength envelopes of ice at various temperatures: $\mathrm{c}, \phi, \mathrm{p}^{*}$, and $\mathrm{T}$ are the ice cohesion, friction angle, ice melting pressure, and absolute temperature, respectively. 
proportional to temperature. It has been shown that the hydrostatic pressure being applied to ice decreases its melting temperature and thus its strength under triaxial compression.

In the present report a different approach has been undertaken. The authors considered the ice strength as a function of two variables: the hydrostatic pressure and temperature, i.e.,

$$
\tau_{\mathrm{i}}^{*}=\tau_{\mathrm{i}}^{*}(p, T) ; \quad \dot{\gamma}_{\mathrm{i}}=\text { Const. }
$$

At a constant strain rate the strength of ice in a multiaxial stress state is described by the parabolic yield criterion with three parameters: the cohesion, and the friction angle, which are different nonlinear functions of temperature, and the ice melting pressure. Then a strength criterion of ice, which takes into account the combined effect of all three variables in eq 1 , the strain rate, hydrostatic pressure and temperature, is obtained by combining eq $1 \mathrm{~b}$ and $1 \mathrm{~d}$.

\section{STRAIN RATE EFFECT}

A constitutive equation for steady-state creep of homogeneous and isotropic ice in a multiaxial stress state at constant strain rate and constant temperature takes the following form (Fish 1991, 1992, 1993):

$$
\dot{\gamma}_{\mathrm{i}}=\frac{\tilde{C}}{t_{\mathrm{o}}}\left(\frac{\tau_{\mathrm{i}}}{\tau_{\mathrm{io}}}\right)^{n}
$$

It should be emphasized that eq 2 is fundamentally different from the Norton-Glen power flow law (eq 1c), although it contains a power function of stress with exponent $n$.

In contrast to eq $1 \mathrm{c}$ parameters $\tilde{C}$ and $t_{\mathrm{o}}$ in eq 2 have a definite physical meaning, and the denominator of the stress function is a temperature-dependent yield criterion (eq 5 below). This yield criterion, which is a function of the first invariant of the stress tensor and temperature, relates the minimum shear strain rate and the shear stress in the whole spectrum of hydrostatic pressures (mean normal stresses).

Equation 2 implies that the nonlinear viscosity coefficient of ice

$$
\eta_{\mathrm{o}}(p, T)=t_{\mathrm{o}} \tau_{\mathrm{io}}^{n} / \tilde{C}
$$

is a function of the hydrostatic pressure and temperature. For $p<\sigma_{\max }$ one can see that the higher the hydrostatic pressure is, the greater the viscosity coefficient, the lower the strain rate of ice, and the higher the ice strength will be. For $p>\sigma_{\max }$ the higher the hydrostatic pressure is, the smaller the viscosity coefficient, the higher the strain rate, and the lower the ice strength will be. This is confirmed well by test data (Jones 1982, Jones and Chew 1983).

Equation 2 can be rewritten in terms of maximum (peak) shear strength $\tau_{\mathrm{i}}^{*}=\tau_{\mathrm{i}}$ and presented as a product of two independent functions: a yield function $\tau_{\text {io }}(p)$ and a nondimensional function $\Phi\left(\dot{\gamma}_{\mathrm{i}}\right)$ of the constant strain rate

$$
\tau_{\mathrm{i}}^{*}\left(p, \dot{\gamma}_{\mathrm{i}}\right)=\tau_{\mathrm{io}}(p) \Phi\left(\dot{\gamma}_{\mathrm{i}}\right) .
$$

Function $\Phi\left(\dot{\gamma}_{\mathrm{i}}\right)$ has been selected in its simplest form:

$$
\Phi\left(\dot{\gamma}_{\mathrm{i}}\right)=\left(\frac{\dot{\gamma}_{\mathrm{i}} t_{\mathrm{o}}}{\gamma_{\mathrm{io}}}\right)^{1 / n}=\left(\frac{\dot{\gamma}_{\mathrm{i}}}{\dot{\gamma}_{\mathrm{io}}}\right)^{1 / n}
$$

where $\dot{\gamma}_{\mathrm{i}}=$ applied octahedral constant shear strain rate

$\dot{\gamma}_{\text {io }}=\gamma_{\text {io }} / t_{\mathrm{o}}=$ instantaneous (referenced) octahedral shear strain rate

$\gamma_{\mathrm{io}}=\tilde{C}=$ instantaneous octahedral shear strain

$n=$ dimensionless parameter; for polycrystalline ice, $n \approx 4$ (Jones 1982)

$t_{\mathrm{O}}=$ temperature-dependent time to failure, i.e., the time interval between the initiation of the test conducted at $\dot{\gamma}_{\mathrm{i}}=\dot{\gamma}_{\text {io }}$ and the moment when the ice strength reaches a maximum (peak) value.

The temperature dependency of $t_{\mathrm{O}}$ is given by

$$
t_{\mathrm{o}}=\frac{h}{k T} \exp \left(\frac{E}{R T}\right)
$$

$$
\text { where } \begin{aligned}
E & =\text { activation energy } \\
R & =\text { gas constant } \\
h & =\text { Planck's constant } \\
k & =\text { Boltzmann's constant. }
\end{aligned}
$$

In eq 3 the "instantaneous" (referenced) octahedral strain rate $\dot{\gamma}_{\text {io }}$ is defined as a strain rate at which the shear strength of ice reaches a maximum value, separating two different modes of failure: the brittle mode dominated by the cleavage mechanism of failure and the ductile mode dominated by the shear mechanism. At strain rates $\left(\dot{\gamma}_{\mathrm{i}}>\dot{\gamma}_{\mathrm{io}}\right)$ the ice strength either decreases (Gagnon 
and Gammon 1995) or remains unchanged (Jones 1982). Apparently, the magnitude of the instantaneous strain rate depends on the type of ice, its structure and other factors and varies between $10^{-1}$ and $10^{-3} \mathrm{~s}^{-1}$. Since the magnitude of ice strength is greatly affected by the strain rate, selection of an adequate value of this referenced strain rate is extremely important for an accurate prediction of the ice strength at lower strain rates.

In experimental studies of ice under triaxial (biaxial) compression, the radial strains are assumed to be small and are usually ignored. In this case eq 3 can be replaced by

$$
\Phi\left(\dot{\gamma}_{\mathrm{i}}\right)=\Phi(\dot{\varepsilon})=\left(\frac{\dot{\varepsilon} t_{\mathrm{O}}}{\varepsilon_{\mathrm{o}}}\right)^{1 / n}=\left(\frac{\dot{\varepsilon}}{\dot{\varepsilon}_{\mathrm{o}}}\right)^{1 / n}
$$

where $\dot{\varepsilon}=$ axial strain rate

$\dot{\varepsilon}_{\mathrm{o}}, \varepsilon_{\mathrm{o}}=$ instantaneous (referenced) axial strain rate and strain respectively.

$t_{\mathrm{o}}=\varepsilon_{\mathrm{o}} / \dot{\varepsilon}_{\mathrm{o}}=$ given by eq 4 .

Thus, the strain rate function varies in the limits

$$
1 \geq \Phi\left(\dot{\gamma}_{\mathrm{i}}\right)=\Phi(\dot{\varepsilon}) \geq 0 .
$$

The effect of the strain rate on the strength of ice can be excluded from consideration by selecting the strength test data of ice corresponding to $\Phi(\dot{\varepsilon})=1$.

\section{EFFECT OF HYDROSTATIC PRESSURE}

When applied strain rate is equal to the instantaneous strain rate $\dot{\gamma}_{i}=\dot{\gamma}_{\text {io }}$ or $\dot{\varepsilon}=\dot{\varepsilon}_{\mathrm{o}}$, in eq 2a and 3a, $\Phi\left(\dot{\gamma}_{\text {io }}\right)=\Phi\left(\dot{\varepsilon}_{\mathrm{o}}\right)=1$, and the strength dependency of ice upon the hydrostatic pressure is described by the parabolic yield criterion (Fish 1991) depicted in Figure 1,

$$
\tau_{\mathrm{io}}(p)=c+b p-\frac{b}{2 \sigma_{\max }} p^{2}
$$

or

$$
\tau_{\mathrm{io}}(p)=(c+b p)-\left(c+b p^{*}\right)\left(\frac{p}{p^{*}}\right)^{2}
$$

where $c=$ ice cohesion on the octahedral plane

$b=\tan \phi$, where $\phi$ is the angle of internal friction of ice on the octahedral plane

$p=\left(\sigma_{1}+\sigma_{2}+\sigma_{3}\right) / 3=$ hydrostatic pressure (mean normal stress)

$\sigma_{1}, \sigma_{2}, \sigma_{3}=$ principal stresses,

$$
\begin{aligned}
\tau_{\mathrm{i}}= & \frac{1}{\sqrt{6}}\left[\left(\sigma_{1}-\sigma_{2}\right)^{2}+\left(\sigma_{2}-\sigma_{3}\right)^{2}\right. \\
\qquad & \left.+\left(\sigma_{1}-\sigma_{3}\right)^{2}\right]^{1 / 2} \\
\sigma_{\max }= & \begin{array}{l}
\text { octahedral shear stress (resultant) } \\
\text { sure at which the shear strength } \\
\text { reaches a maximum }
\end{array} \\
\tau_{\max }= & c+\frac{b}{2} \sigma_{\max } \\
\sigma_{\max }= & \frac{p^{* 2}}{2\left(\frac{c}{b}+p^{*}\right)} \\
p^{*}= & \text { ice melting pressure at which the } \\
& \text { shear strength of ice equals to zero. }
\end{aligned}
$$

Subscript (o) at $\tau_{\text {io }}$ in eq 5 indicates that parameters $c$ and $b$ are referred to the instantaneous condition when the applied strain rate is equal to the instantaneous strain rate.

Note that the yield curve may also intersect the hydrostatic axis in the domain of the negative hydrostatic pressures $(-p)$ at point $h_{2}$ (not shown in Fig. 1), the abscissa of which is equal to

$$
h_{2}=\frac{-p^{*}}{1+\frac{b}{c} p^{*}} .
$$

Equation 5 can be considered an extended Von Mises-Drucker-Prager yield criterion. At low stress level $p<<\sigma_{\max }$ the third term in the right side of eq 5 approaches zero and eq 5 transforms into the Drucker-Prager (1952) (extended Von Mises) yield criterion:

$$
\tau_{\text {io }}=c+b p .
$$

For frictionless materials $(b=0)$ eq 5 reduces to the Von Mises yield criterion

$$
\tau_{\mathrm{io}}=c \text {. }
$$

Thus, in a multiaxial stress state, the strength of ice as well as its strength characteristics are functions of only three parameters: $p^{*}, c$ and $b$ which all have a definite physical meaning and are easily determined from test data. Studies show that all these parameters are functions of temperature, i.e.,

$$
p^{*}=p^{*}(T), \quad c=c(T), \quad b=b(T) .
$$

Consequently, the shear strength of ice as well as the strength characteristics of ice are also functions of temperature: 


$$
\begin{aligned}
\tau_{\text {io }} & =\tau_{\text {io }}(T), \quad \tau_{\max }=\tau_{\max }(T), \\
\sigma_{\max } & =\sigma_{\max }(T), \quad h_{2}=h_{2}(T) .
\end{aligned}
$$

Thus, if a series of strength tests of ice is carried out at a constant strain rate instead of one yield curve, one obtains a family of curves for various temperatures (Fig. 1). It should be emphasized that parameters $c, b$ and $\tau_{\max }$ are also strain-rate dependent, while parameters $\sigma_{\max }, p^{*}$ and $h_{2}$ are independent of the strain rate (Fish 1992, 1993).

\section{TEMPERATURE EFFECT}

\section{Ice melting pressure}

It is well known that the ice melting temperature, as well as the melting temperature of other crystalline materials, is a function of the hydrostatic pressure. This pressure can be determined (Zaretsky and Fish 1996a) from the Clapeyron equation, according to which a small change in the equilibrious melting temperature of a solid $\Delta T_{\mathrm{m}}$ attributable to a small change in the hydrostatic pressure $\Delta p$ can be calculated from the relationship

$$
d T_{\mathrm{m}}=\frac{V_{\ell}-V_{\mathrm{s}}}{S_{\ell}-S_{\mathrm{s}}} d p=T_{\mathrm{m}} \frac{V_{\ell}-V_{\mathrm{s}}}{L_{\mathrm{m}}} d p
$$

where $V_{\ell}$ and $V_{\mathrm{s}}=$ unit mass volume of the material in the liquid and in the solid state, respectively

$S_{\ell}$ and $S_{\mathrm{s}}=$ unit mass entropy of the liquid and of the solid state, respectively

$L_{\mathrm{m}}=$ specific heat of melting of the unit mass.

Since at melting the volume $V_{\ell}<V_{\mathrm{s}}, d T_{\mathrm{m}}<0$, i.e., the equilibrious melting temperature of ice $T_{\mathrm{m}}$ decreases as well,

$$
d T_{\mathrm{m}}=-A d p
$$

Thus, for ice when $p=0, T_{\mathrm{m}}=273.1 \mathrm{~K}, V_{\ell}=10^{-3}$ $\mathrm{m}^{3} \mathrm{~kg}^{-1}, V_{\mathrm{s}}=1.09 \times 10^{-3} \mathrm{~m}^{3} \mathrm{~kg}^{-1}, L_{\mathrm{m}}=3.336 \times 10^{5}$ $\mathrm{J} \mathrm{kg}^{-1}$, and parameter $A$ for ice at temperature $\theta=0^{\circ} \mathrm{C}$ is equal to

$$
A=0.074 \mathrm{~K} / \mathrm{MPa} \text {. }
$$

The magnitude of parameter $A$ coincides with that calculated by Barnes et al. (1971). It is not difficult at this point to calculate the critical hy- drostatic pressure $p^{*}$ at which the shear resistance of ice equals zero, i.e.,

$$
T_{\mathrm{m}}+\theta=T_{\mathrm{m}}-A p^{*}
$$

and

$$
p^{*}=\frac{-\theta}{A}
$$

where $\theta=$ ice temperature $\left({ }^{\circ} \mathrm{C}\right)$ and $T_{\mathrm{m}}=273.1 \mathrm{~K}$ is the ice melting temperature at the atmospheric pressure. Note that the ice melting pressure is unrelated to the grain size or the structure of ice. The magnitudes of ice melting pressures $p^{*}$ for various temperatures are presented in Table 1.

\section{Ice cohesion}

The ice cohesion defines the ice strength when the hydrostatic pressure $p=0$. Ice strength is a stochastic event, a culmination point of failure of intermolecular bonds and growth of cracks. A certain number of these bonds in the unit volume of ice are formed during freezing of water at temperature $0^{\circ} \mathrm{C}$. Further temperature decrease brings about formation of new bonds, attributable to freezing of the liquid phase on grain boundaries, and a sharp increase of the ice strength (cohesion). Thus, one may conclude that the ice cohesion is a function of temperature and consists of a sum of two components:

$$
c(T)=c_{\mathrm{o}}+c_{1}(T)
$$

where $c_{\mathrm{o}}$ is the component of the ice cohesion brought about at the time of ice formation at $0^{\circ} \mathrm{C}$ and $c_{1}(T)$ is the temperature-dependent component of the cohesion brought about by freezing of liquid phase at temperature below $0^{\circ} \mathrm{C}$.

Since the physical nature of $c_{0}$ and $c_{1}$ is the same, and taking into account that at temperature $T=T_{\mathrm{m}}, c_{1}=0$, the temperature dependency of component $c_{1}$ can be presented in the form

$$
c_{1}(T)=c_{\mathrm{o}} \alpha\left(1-T / T_{\mathrm{m}}\right)
$$

where $\alpha$ is a parameter. Combining eq 15 and 16

$$
c(T)=c_{\mathrm{o}}\left[1+\alpha\left(1-T / T_{\mathrm{m}}\right)\right] .
$$

Equation 17 establishes a linear dependency of the ice cohesion upon temperature. Test data show that such a relationship is valid in the domain of relatively low temperatures below $-20^{\circ} \mathrm{C}$. In the range of moderate temperature, this relationship becomes nonlinear and somewhat better 


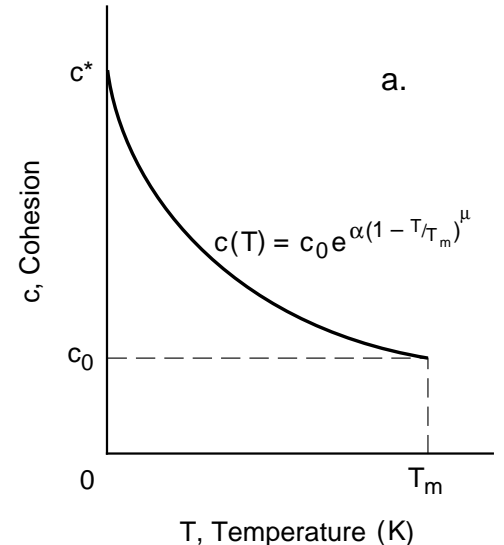

Temperature $(\mathrm{K})$

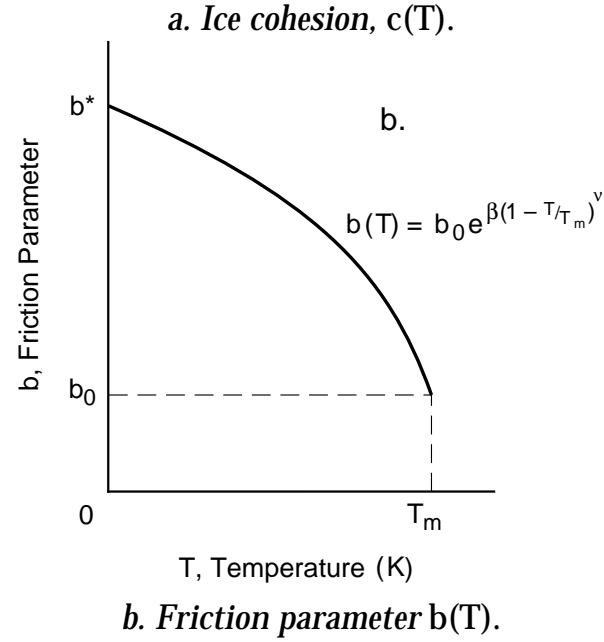

Figure 2. Temperature diagrams of the strength parameters of ice.

described by

or

$$
c(T)=c_{\mathrm{o}} e^{\alpha\left(1-T / T_{\mathrm{m}}\right)^{\mu}}
$$

$$
c(\theta)=c_{\mathrm{o}} e^{\alpha|\theta| / T_{\mathrm{m}}}
$$

in which $\mu=1$ and $|\theta|=\left(T_{\mathrm{m}}-T\right)$ is ice temperature $\left({ }^{\circ} \mathrm{C}\right)$.

Equations 18 and 18a can be considered approximate forms of eq 17. Note that at freezing

$$
T=T_{\mathrm{m}}=273.1 \mathrm{~K}\left(0^{\circ} \mathrm{C}\right) ; c(0)=c_{\mathrm{o}}
$$

when

$$
T=0\left(-273.1^{\circ} \mathrm{C}\right) ; c^{*}=c_{\mathrm{o}} e^{\alpha} .
$$

The temperature diagram of parameter $c$ is shown in Figure 2a.

\section{Angle of internal friction}

The parameter of internal friction of ice $b(T)$ can also be presented as a sum of two components:

$$
b(T)=b_{\mathrm{O}}+b_{1}(T)
$$

where $b_{\mathrm{o}}=\tan \phi_{\mathrm{o}}$ and $\phi_{\mathrm{o}}$ is the angle of internal friction of ice brought about at the time of ice formation at $0^{\circ} \mathrm{C} ; b_{1}(T)=\tan \phi_{1}(T)$, and $\phi_{1}(T)$ is the angle of internal friction attributable to the increased viscosity of the liquid phase (lubricant) at grain boundaries at temperatures below $0^{\circ} \mathrm{C}$.

One may assume that the component $b_{1}(T)$ is proportional to $b_{\mathrm{o}}$ and to the temperature melting function, i.e.,

$$
b_{1}(T)=b_{\mathrm{o}} \beta\left(1-T / T_{\mathrm{m}}\right)
$$

where $\beta$ is a parameter. Combining eq 19 and 20

$$
b(T)=b_{\mathrm{o}}\left[1+\beta\left(1-T / T_{\mathrm{m}}\right)\right] .
$$

To simplify the parameter evaluation procedure, eq 21 can approximately be presented in the form

$$
\begin{aligned}
& b(T)=b_{\mathrm{o}} e^{\beta\left(1-T / T_{\mathrm{m}}\right)^{\nu}} \\
\text { or } \quad b(\theta) & =b_{\mathrm{o}} e^{\beta_{1}|\theta|^{v}}
\end{aligned}
$$

where $\beta_{1}=\beta / T_{\mathrm{m}}^{v}$. It was found that $v=1 / 2$ is in agreement with test data.

At freezing when

$$
T=T_{\mathrm{m}}=273.1 \mathrm{~K}\left(0^{\circ} \mathrm{C}\right) ; \quad b(0)=b_{\mathrm{o}}
$$

at the absolute zero

$$
T=0\left(-273.1^{\circ} \mathrm{C}\right) ; b^{*}=b_{\mathrm{o}} e^{\beta}
$$

The temperature diagram of parameter $b(T)$ is given in Figure $2 b$. Note that at very low temperatures certain adjustments of eq 15 through 22 will probably be required.

\section{TEMPERATURE CRITERIA OF ICE STRENGTH}

Since temperature dependencies of the ice strength parameters have been established, eq 1d taking into account eq 5 can be presented in an explicit form

$$
\tau_{\text {io }}(p, T)=c(T)+b(T) p-\frac{b(T)}{2 \sigma_{\max }(T)} p^{2}
$$

in which $c(T), b(T)$ and $\sigma_{\max }(T)$ are given by eq 7 and 14 through eq 22a. Equation 23 is a temperature criterion of ice strength in a multiaxial stress state. To take into account the strain rate effect, eq 
23 should be combined with eq 2 a through 4 . Then eq 1 can be written as

$$
\begin{aligned}
\tau_{\mathrm{i}}^{*}(p, \dot{\varepsilon}, T) & =\tau_{\mathrm{io}}(p, T) \Phi(\dot{\varepsilon}) \\
& =\left(c(T)+b(T) p-\frac{b(T)}{2 \sigma_{\max }(T)} p^{2}\right)\left(\frac{\dot{\varepsilon}}{\dot{\varepsilon}_{\mathrm{o}}}\right)^{1 / n}
\end{aligned}
$$

In the range of the hydrostatic pressures $p<<$ $\sigma_{\max }$ eq 24 takes the form

$$
\tau_{\mathrm{i}}^{*}(p, \dot{\varepsilon}, T)=[c(T)+b(T) p]\left(\frac{\dot{\varepsilon}}{\dot{\varepsilon}_{\mathrm{o}}}\right)^{1 / n}
$$

when $p=0$ (pure shear)

$$
\tau_{\mathrm{i}}^{*}(\dot{\varepsilon}, T)=c(\dot{\varepsilon}, T)=c(T)\left(\frac{\dot{\varepsilon}}{\dot{\varepsilon}_{\mathrm{O}}}\right)^{1 / n}
$$

Accordingly

$$
b(\dot{\varepsilon}, T)=b(T)\left(\frac{\dot{\varepsilon}}{\dot{\varepsilon}_{\mathrm{o}}}\right)^{1 / n}
$$

where parameters $c(T)$ and $b(T)$ are corresponding to the strain rate $\dot{\varepsilon}=\dot{\varepsilon}_{\mathrm{o}}$.

If the radial strain rates are taken into account function $\Phi(\dot{\varepsilon})$ in eq 24,25 and 26 should be replaced by function $\Phi(\dot{\gamma})$.

\section{TEST DATA}

The validity of the temperature dependencies of the strength parameters of ice presented above was verified using test data of Gagnon and Gammon (1995). The triaxial $\left(\sigma_{2}=\sigma_{3}\right)$ compression tests were carried out using cylindrical specimens of Labrador iceberg ice, $9.58 \mathrm{~cm}$ in diameter and $26 \mathrm{~cm}$ long. Mean grain diameter $d \approx 8.1 \mathrm{~mm}$. The test temperature varied between $-1^{\circ} \mathrm{C}$ and $-16^{\circ} \mathrm{C}$. The tests were conducted at constant axial strain rates between $10^{-2}$ and $10^{-5} \mathrm{~s}^{-1}$. Test data corresponding to the strain rate $\dot{\varepsilon}_{\mathrm{o}} \approx 5 \times 10^{-3} \mathrm{~s}^{-1}$ were selected in the following analysis to evaluate the strength parameters of ice. This strain rate was defined by the authors of this report as the instantaneous strain rate because the test strength magnitudes at this rate reached their maximum values. The tests were carried out at four different confining pressures: 1.38, 3.45, 6.89 and $13.79 \mathrm{MPa}$. The test data replotted by the authors of this report in terms of the shear strength $\tau_{\mathrm{i}}=\left(\sigma_{1}-\sigma_{3}\right) / \sqrt{3}$ vs. the hydrostatic pressure $p=\left(\sigma_{1}+\sigma_{2}+\sigma_{3}\right) / 3$ are presented in Figure 3. Note that each point in Figure 3 represents the mean of five tests.

In Figure 3 for comparison tests, data are presented on triaxial compression of freshwater polycrystalline ice obtained by Jones (1982). The ran-

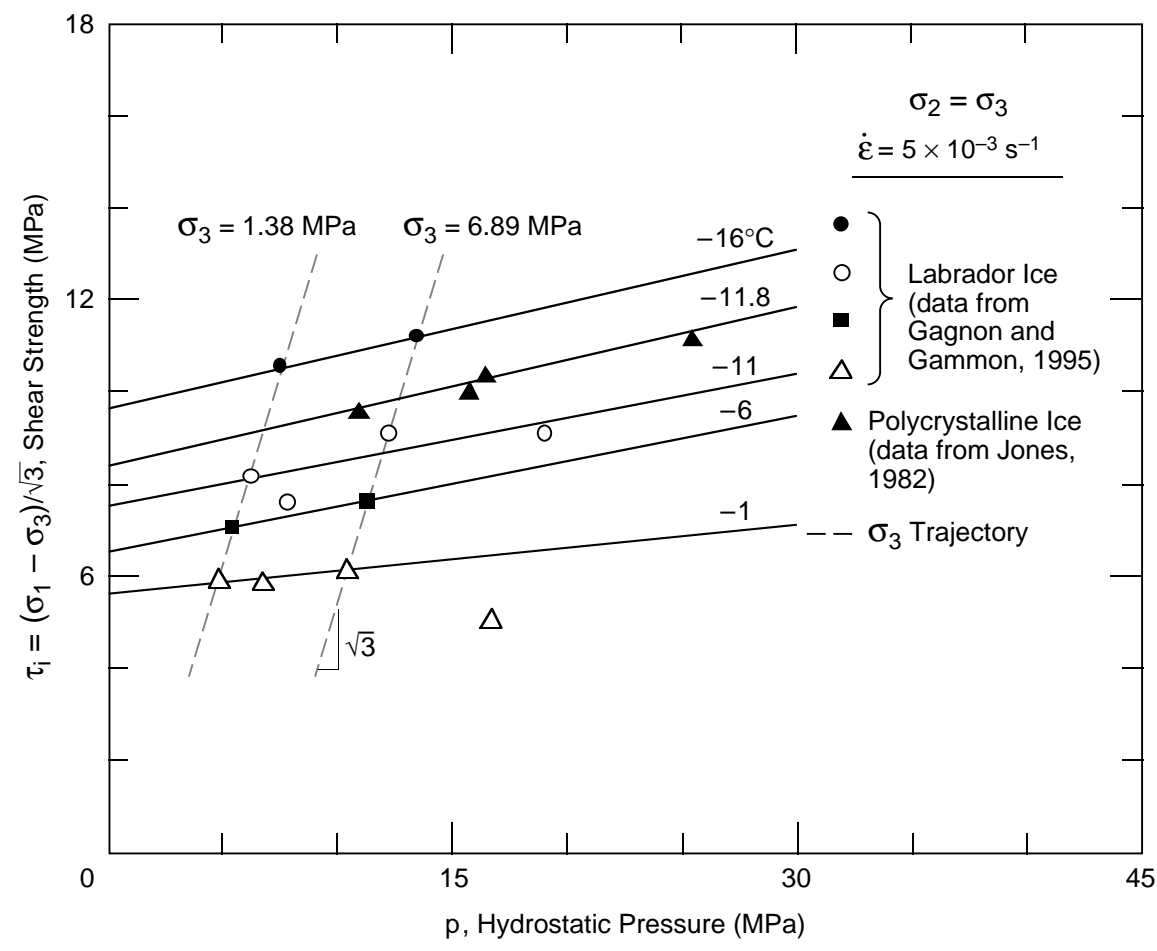

Figure 3. Strength test data of ice under triaxial compression. Data from Gagnon and Gammon (1995) and Jones (1982). 
domly oriented laboratory-made ice samples were $20 \mathrm{~mm}$ in diameter and 60 $\mathrm{mm}$ long with mean grain diameter less than $1 \mathrm{~mm}$. The test data selected for comparison refer to the axial constant strain rate $\dot{\varepsilon}=5.4 \times 10^{-3} \mathrm{~s}^{-1}$. The test temperature was $-11.8 \pm 0.9^{\circ} \mathrm{C}$. The confining pressure $\left(\sigma_{2}=\sigma_{3}\right)$ varied between $\sim 5$ and $\sim 85 \mathrm{MPa}$.

In Figure 10 (below), results of triaxial constant strain rate compression tests are presented of freshwater, randomly oriented, polycrystalline ice carried out by Rist and Murrell (1994). In these tests laboratory-made samples of ice were $40 \mathrm{~mm}$ in diameter and $100 \mathrm{~mm}$ long. Mean grain diameter was $\sim 1.7 \mathrm{~mm}$. The tests were conducted at constant strain rates from $10^{-2}$ to $10^{-5} \mathrm{~s}^{-1}$; the test temperatures varied between $-20^{\circ}$ and $-45^{\circ} \mathrm{C}$. The data selected for this analysis are referred to as the axial strain rate, $\dot{\varepsilon} \sim 10^{-3} \mathrm{~s}^{-1}$.

\section{PARAMETER EVALUATION}

Temperature variations of ice strength in a multiaxial stress state were shown to be defined by three temperature-dependent parameters: the ice melting pressure $p(T)$, ice cohesion $c(T)$ and friction parameter $b(T)$. The magnitudes of the ice melting pressure $p(T)$ were calculated by eq 14 for the test temperatures and are included in Table 1 . The magnitudes of $p^{*}$ for $\theta=-11.8^{\circ} \mathrm{C}$ was found to be in agreement with $p^{*}=123.7$ MPa obtained earlier (Fish 1991) from the analysis of Jones' data and with that calculated by an empirical equation of Hallam and Nadreau (1988).

The temperature dependencies of parameters $c(\theta)$ and $b(\theta)$ can be determined based upon the considerations that in the range of low hydrostatic pressures $p$ $\ll \sigma_{\max }$ (test pressures in Fig. 3). As a first approximation, eq 5 can be replaced by eq 9 . Then, the slopes of the straight lines and their intersects with the ordinate axis obtained by a regression analysis of the test data define the magnitudes of friction parameter $b(\theta)$ and cohesion $c(\theta)$ for corresponding temperatures. The results of the analysis are presented in Figure 4.

One can see in Figure 4 that temperature dependencies of parameters $c$ and $b$
Table 1. Strength parameters of ice at various temperatures*.

\begin{tabular}{lcccccc}
$\theta^{\circ} \mathrm{C}$ & $\mathrm{c}(\mathrm{MPa})$ & $\mathrm{b}$ & $\sim \phi^{\circ}$ & $\sigma_{\max }(\mathrm{MPa})$ & $\tau_{\max }(\mathrm{MPa})$ & $\mathrm{p}^{*}(\mathrm{MPa})$ \\
\hline-40 & $12.93^{\dagger}$ & 0.241 & 14 & 245.87 & 43.52 & 540.54 \\
-16 & 9.43 & 0.125 & 7 & 80.15 & 14.44 & 216.22 \\
-11.8 & 8.14 & 0.106 & 6 & 53.81 & 10.99 & 159.46 \\
-11 & 7.91 & 0.103 & 6 & 49.0 & 10.43 & 148.65 \\
-6 & 6.63 & 0.08 & $4^{\circ} 30^{\prime}$ & 20.05 & 7.43 & 81.08 \\
-1 & 5.56 & 0.053 & 3 & $(4.79)^{* *}$ & $(5.69)^{* *}$ & $(36.85)^{* *}$ \\
0 & $5.37^{++}$ & $0.04^{++}$ & $2^{++}$ & & & \\
\hline
\end{tabular}

* Data in this table for strain rate $\dot{\varepsilon} \approx 5 \times 10^{-3} \mathrm{~s}^{-1}$.

+ Calculated by eq 17.

** From the best fit of eq 5 .

${ }^{+t}$ At freezing.

are indeed nonlinear and can be described by eq 18a and 22a. The evaluation procedures of parameters that enter these equations are shown in Figures 5 and 6. It was found that for the Labrador iceberg ice

$$
\begin{array}{ll}
c_{\mathrm{o}}=5.37 \mathrm{MPa} ; & b_{\mathrm{o}}=0.04 \\
\alpha=9.61 ; & \beta=4.69 .
\end{array}
$$

Using these parameters, we calculated the magnitudes of the ice cohesion $c(\theta)$, the friction parameter $b(\theta)$ and the friction angle $\phi(\theta)$ by eq 18a and 22a (Table 1). The magnitudes of $\sigma_{\max }(\theta)$ and

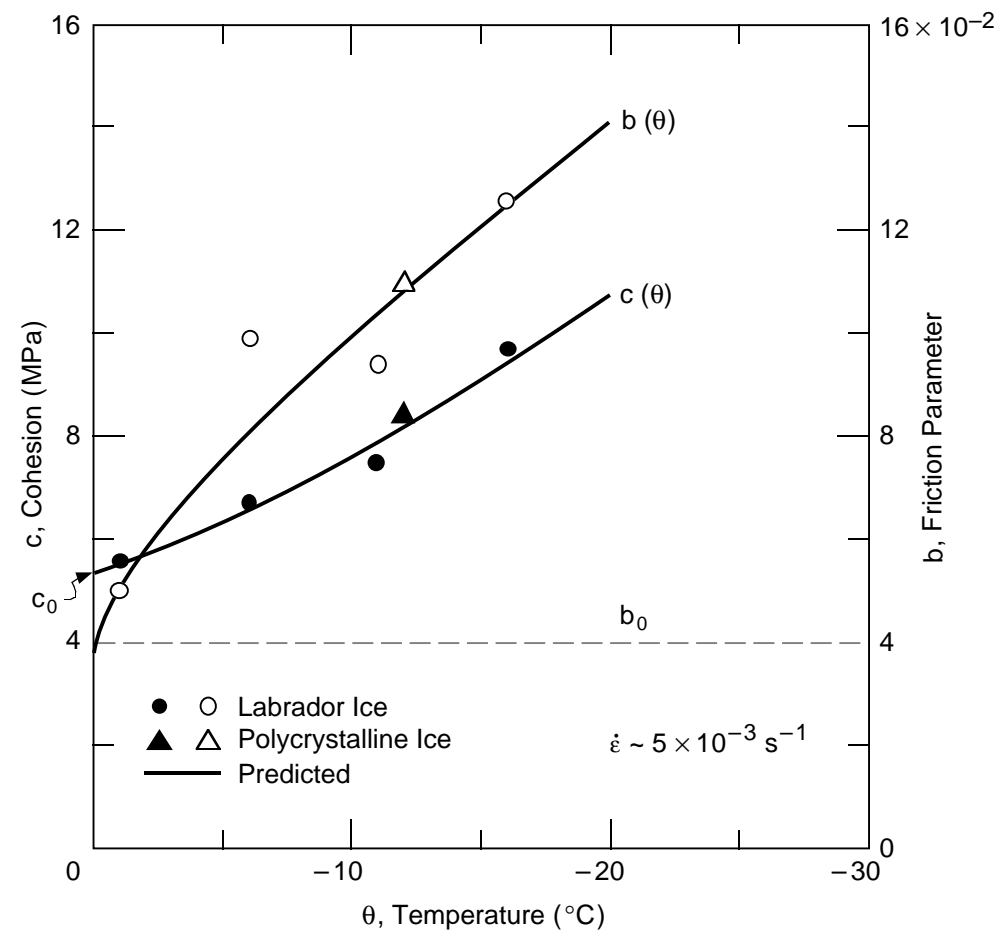

Figure 4. Temperature dependencies of the strength parameters of ice. Data from Gagnon and Gammon (1995) and Jones (1982). 


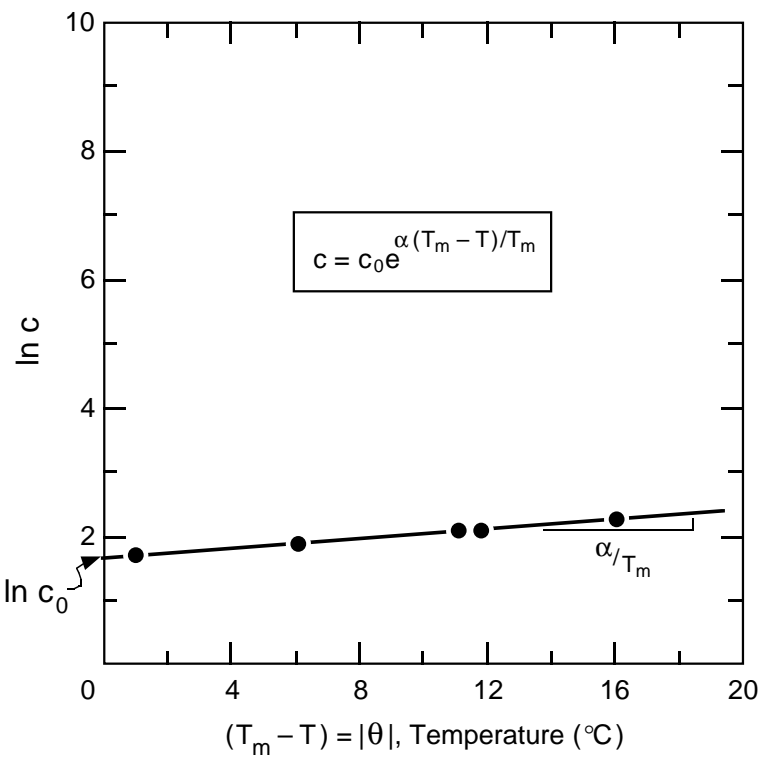

Figure 5. Determination of parameters $\mathrm{c}_{\mathrm{o}}$ and $\alpha$.

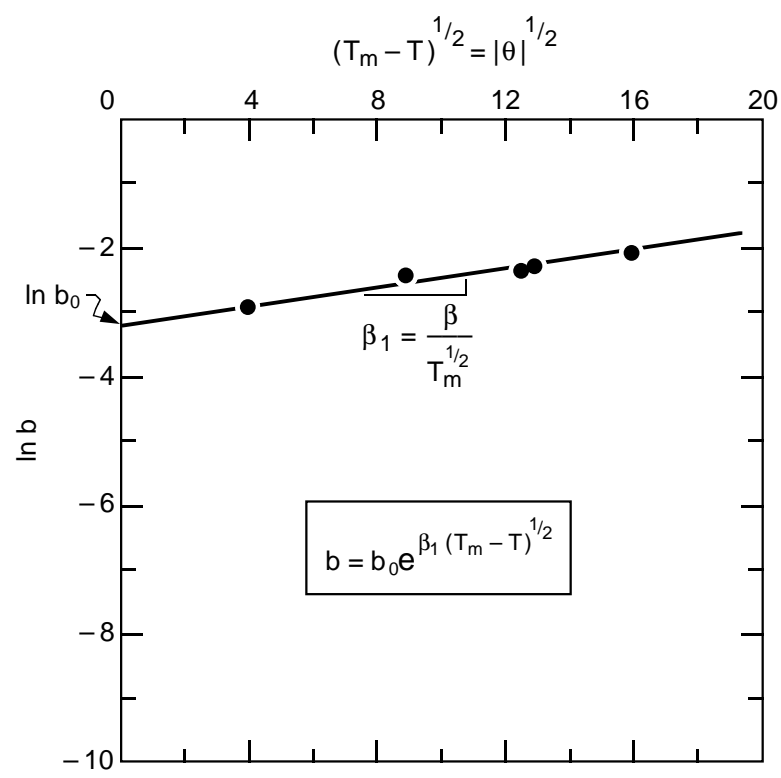

Figure 6. Determination of parameters $\mathrm{b}_{\mathrm{o}}$ and $\beta$.

$\tau_{\max }(\theta)$ in Table 1 were calculated by eq 6 and 7 using corresponding values of $c(\theta), b(\theta)$ and $p^{*}(\theta)$. Predicted temperature dependencies of parameters $c$ and $b$ are presented in Figure 4. From Table 1 and Figure 4, it follows that major changes of parameters $b$ and $c$, and ice strength take place at temperature below $-10^{\circ} \mathrm{C}$. Between $-10^{\circ}$ and $-12^{\circ} \mathrm{C}$ the ice strength changes insignificantly.

It is curious to compare, at least approximately, parameter $b(T)$ and the kinetic friction coefficient $\mu_{c}$ of ice, although the physical nature of these two parameters is quite different. Thus, Jones et al. (1991) reported that for $\theta=-10^{\circ} \mathrm{C}$ and for the sliding velocity of $10^{-3} \mathrm{~m} \mathrm{~s}^{-1}, \mu_{\mathrm{c}} \approx 0.13$. In Table 1 we found that for $-10^{\circ} \mathrm{C}, b=0.098$ that is in agreement with the test data.

Comparing parameter $b_{\mathrm{o}}$ with the kinetic dry friction coefficient $\mu_{\mathrm{d}}$ of ice on ice is particularly interesting. Since the latter is temperature-dependent, the comparison should be made for a low ice temperature when the effect of the liquid phase (lubricant) is minimal. Thus, from Casassa et al. (1991) we find that for $\theta=-35^{\circ} \mathrm{C}, \mu_{\mathrm{d}}=0.019$, which is in correlation with $b_{\mathrm{o}}=0.04$ obtained above. Obviously a more accurate comparison would require certain adjustments of both parameters to account for the differences in the test velocities.

Note that a seeming contradiction may arise when one compares the ice strength values in Table 1 with eq 5 a. From Table 1 it follows that ice possesses a certain strength at $0^{\circ} \mathrm{C}$. On the other hand, from a comparison of eq $5 \mathrm{a}$ and 14 one concludes that the shear strength of ice at this temperature should be zero. Such a contradiction arises from a peculiar property of ice: ice is formed and melts at the same temperature, $0^{\circ} \mathrm{C}$. This contradiction is easily eliminated when one remembers that melting of ice (in accordance with eq $5 \mathrm{a}$ ) will take place over a certain time.

\section{ICE COHESION}

Ice cohesion is the principal strength parameter of ice; therefore, it is important to examine the relationship of ice cohesion with the other physical characteristics of ice, such as the grain size, ice structure, etc. Although we have limited information on the effects of these factors on the behavior of ice under triaxial compression, some preliminary conclusions can still be made. Note, in Figures 4, 5 and 6, test points corresponding to Jones' (1982) tests on polycrystalline ice with the grain size of less than $1 \mathrm{~mm}$ follow the same trends as the test data of Gagnon and Gammon on the Labrador ice with an average grain size of $8.1 \mathrm{~mm}$, i.e., eight times larger than the ice in Jones' tests. Such correlation suggests that the ice cohesion magnitudes may not be sensitive to variations of the grain size.

To make sure that this conclusion extends beyond the temperature range between $-1^{\circ}$ and $-16^{\circ} \mathrm{C}$, and that it is valid in the strain rate range different from $\sim 5 \times 10^{-3} \mathrm{~s}^{-1}$ used above in the evaluation of the cohesion, a comparative analy- 
sis of ice strength was carried out using test data of Rist and Murrell (1994). This polycrystalline ice had a grain size of $1.7 \mathrm{~mm}$. The comparison was performed for temperature $-20^{\circ} \mathrm{C}$ and the strain rate range between $\sim 10^{-3} \mathrm{~s}^{-1}$ and $\sim 10^{-5} \mathrm{~s}^{-1}$. The results of the analysis confirmed the above conclusion. At the same time our studies indicate that the ice cohesion magnitude is strongly dependent on the ice structure.

\section{ANGLE OF INTERNAL FRICTION}

From the above studies an important conclusion can also be made regarding the physical nature of the angle of internal friction of ice. While the temperature dependency of the friction parameter $b(\theta)=\tan \phi(\theta)$ is nonlinear (Fig. 4), the test data from Table 1 plotted in Figure 7 suggest that the friction angle is a simplest linear function of temperature:

$$
\phi(\theta)=\phi_{\mathrm{o}}+\omega|\theta|
$$

where $\phi_{\mathrm{o}}=2^{\circ} 50^{\prime}, \omega=16.4^{\prime}$ degree $^{-1}$ and $|\theta|=\left(T_{\mathrm{m}}\right.$ $-T)$ is ice temperature $\left({ }^{\circ} \mathrm{C}\right)$. It should be remembered that the magnitudes of the parameters in eq 27 refer to a strain rate $\dot{\varepsilon} \sim 10^{-3} \mathrm{~s}^{-1}$.

Note that the magnitudes of the internal friction angles $\phi$ in Table 1 and Figure 7 were calculated based mainly upon test data on the Labrador iceberg ice $(d=8.1 \mathrm{~mm})$ at the temperature range between $-1^{\circ}$ and $-16^{\circ} \mathrm{C}$. These data were extrapolated to calculate the friction angle $\phi$ and the ice strength for temperature $-40^{\circ} \mathrm{C}$ (Fig. 7) and compared (see Fig. 10 below) with test data of Rist and Murrell (1994) obtained for this temperature and for the grain size of $1.7 \mathrm{~mm}$.

One can see that despite the considerable difference (almost five times) in the grain sizes of these two types of ice and the difference in the test temperatures, the predicted angle of internal friction correlates well with the test data. We find the friction angle magnitudes are unaffected by variations of the grain size of ice.

Thus, eq 27 can be used for calculations of parameter $b(T)$ in the above equations and for prediction of the ice strength over a wide spectrum of temperatures between $0^{\circ}$ and $-40^{\circ} \mathrm{C}$. It should be remembered that the ice friction angle is a function of the strain rate as well. It decreases rapidly with the strain rate decrease. Fish (1991, 1993) showed that at low strain rates $\sim 10^{-7} \mathrm{~s}^{-1}$ and below, ice at $-10^{\circ} \mathrm{C}$ can be considered as an ideally cohesive $(\phi=0)$ material, the strength of which is defined by eq 10 and 26. At high temperatures the internal friction angle is small and so is its effect on the ice strength. However, at low temperatures or at high strain rates and high confining pressures, the effect of the internal friction angle on the strength of ice can be considerable.

Since parameters $c, b$ and $p^{*}$ were found to be unaffected by variations of the grain size. Table 1 data can be used to predict strength of various

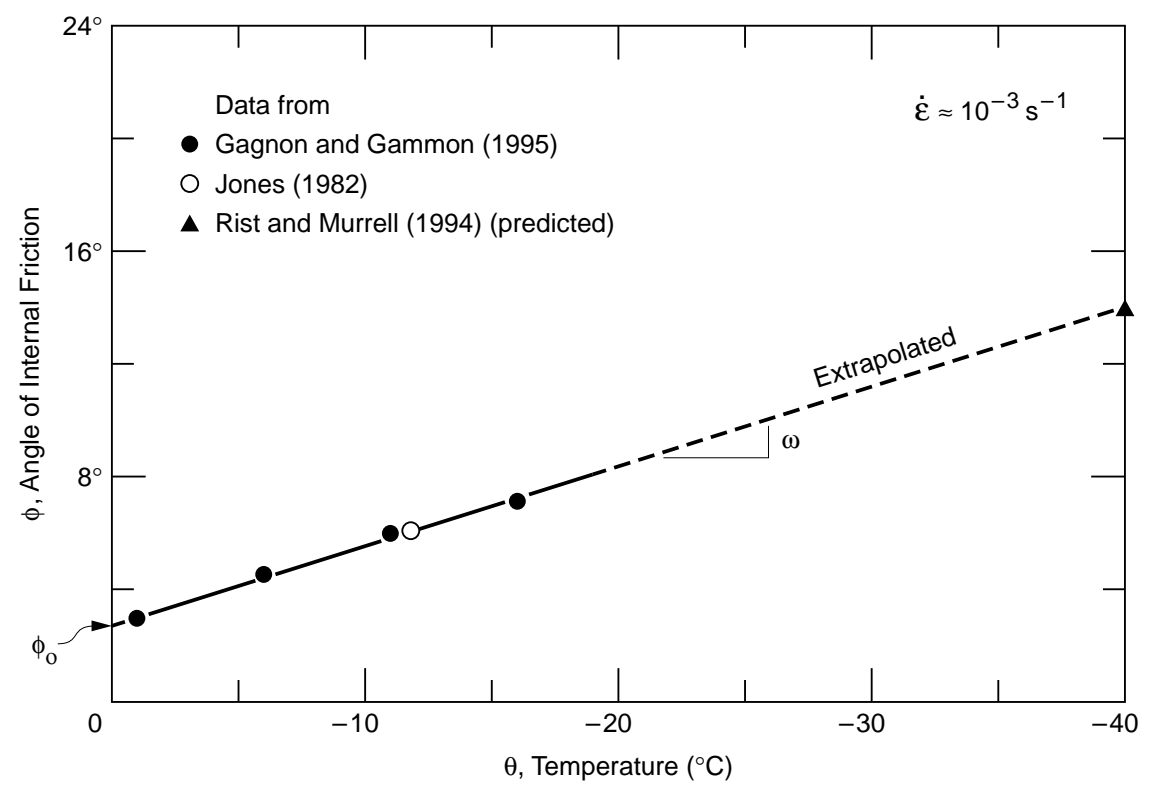

Figure 7. Angle of internal friction of ice as a function of temperature. Data from Gagnon and Gammon (1995), Jones (1982), and Rist and Murrell (1994). 
types of iceberg ice and freshwater randomly oriented polycrystalline ice in a multiaxial stress state.

\section{STRENGTH PREDICTIONS}

Let us verify the accuracy of strength prediction by comparing the computed and the test results of ice strength as functions of temperature, strain rate and hydrostatic pressure.

For low hydrostatic pressures $p<<\sigma_{\max }$ and the strain rate $\dot{\varepsilon}=\dot{\varepsilon}_{\mathrm{O}}$, ice strength can be calculated by eq 9 using data of Table 1 and the hydrostatic pressure magnitudes $p$ from Figure 3, corresponding to confining pressures $\sigma_{3}=1.38 \mathrm{MPa}$ and $6.89 \mathrm{MPa}$. The results of such calculations for the temperature range between $-1^{\circ}$ and $-16^{\circ} \mathrm{C}$ are presented in Figure 8 together with the test data from Gagnon and Gammon (1995). One can conclude that the predicted ice strength values are in agreement with the test data.

The data in Table 1 can also be used to evaluate the ice strength in those cases when the strain rate $\dot{\varepsilon}<\dot{\varepsilon}_{\mathrm{o}}$. For $p<<\sigma_{\max }$ the ice strength is calculated by eq 25 . To simplify the comparison with the published data, the latter can be rewritten in terms of deviator stress:

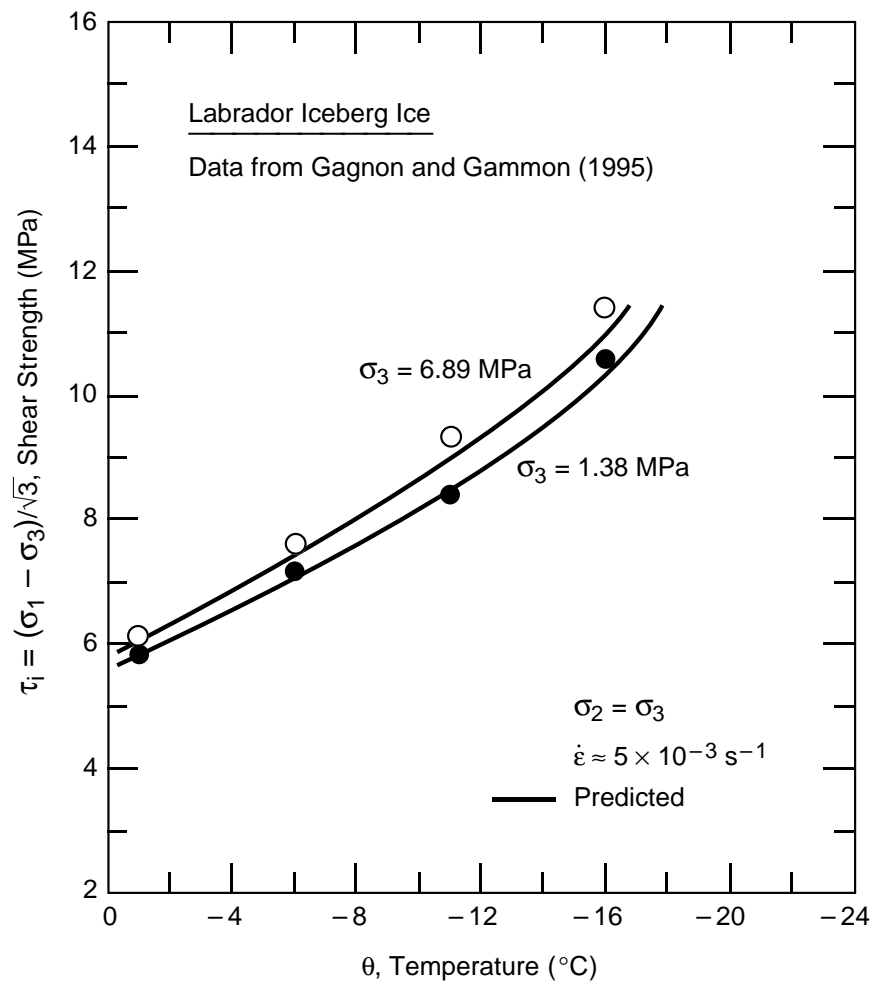

Figure 8. Strength of ice as a function of temperature and confining pressure. Data from Gagnon and Gammon (1995).
Table 2. Strength predictions of Labrador iceberg ice.

\begin{tabular}{cccccc}
$\theta$ & $\begin{array}{c}\text { Confining } \\
\text { pressure }\end{array}$ & $\begin{array}{c}\text { Strain } \\
\text { rate } \dot{\varepsilon} \\
\left(\mathrm{s}^{-1}\right)\end{array}$ & \multicolumn{2}{c}{$\sigma_{1}-\sigma_{3}(\mathrm{MPa})$} & \\
\cline { 5 - 6 }$\left({ }^{\circ} \mathrm{C}\right)$ & $(\mathrm{MPa})$ & Measured & Predicted & Ice type \\
\hline-11 & 1.38 & $4.8210^{-5}$ & 3.50 & 4.36 & Labrador ice \\
-11 & 6.89 & $5.9610^{-5}$ & 4.75 & 4.93 & Labrador ice \\
\hline
\end{tabular}

$$
\sigma_{1}-\sigma_{3}=\sqrt{3}(c+b p)\left(\frac{\dot{\varepsilon}}{\dot{\varepsilon}_{\mathrm{o}}}\right)^{1 / n} .
$$

In Table 2 the results of such calculations are presented for $n=4, \dot{\varepsilon}_{\mathrm{O}}=5 \times 10^{-3} \mathrm{~s}^{-1}$, two different confining pressures (assuming that $p=\sigma_{3}$ ), and two different strain rates together with the test results from Table 2 of Gagnon and Gammon (1995).

From Table 2 it follows that predicted values of ice strength practically coincide with the test data. Unfortunately only two tests of this ice type were available for comparison.

In Figure 9 predicted dependencies of the ice strength are presented calculated by eq 5 using test values of hydrostatic pressures and the strength parameters from Table 1. One can see that in the moderate temperature range between $-6^{\circ}$ and $-16^{\circ} \mathrm{C}$ the calculated values of the ice strength are in good agreement with test data of Gagnon and Gammon (1995). An exception is the test data for $-1^{\circ} \mathrm{C}$ for which the magnitude of the ice melting pressure $p^{*}=13.51$ $\mathrm{MPa}$ calculated by eq 14 turned out to be considerably smaller than $p^{*}=36.85 \mathrm{MPa}$ obtained from the best fit of the experimental points in eq 5. Apparently, as the ice temperature approaches the ice melting temperature, the relationship between the ice melting pressure and temperature becomes nonlinear. Further studies of the temperature-dependency of the ice melting pressure are obviously necessary.

Equation 5 and the data in Table 1 were used to predict the ice strength over the range of high hydrostatic pressures. The results of such an extrapolation are presented in Figure 10 and compared with test data of Jones (1982) for temperature $-11.8^{\circ} \mathrm{C}$, and of Rist and Murrell (1994) for temperature $-40^{\circ} \mathrm{C}$. In the latter case parameter $c$ was calculated by eq 17 to fit the test data, suggesting that further studies of the temperature dependency of ice cohesion in the temperature domain below $-20^{\circ} \mathrm{C}$ are required. At the same time the gen- 


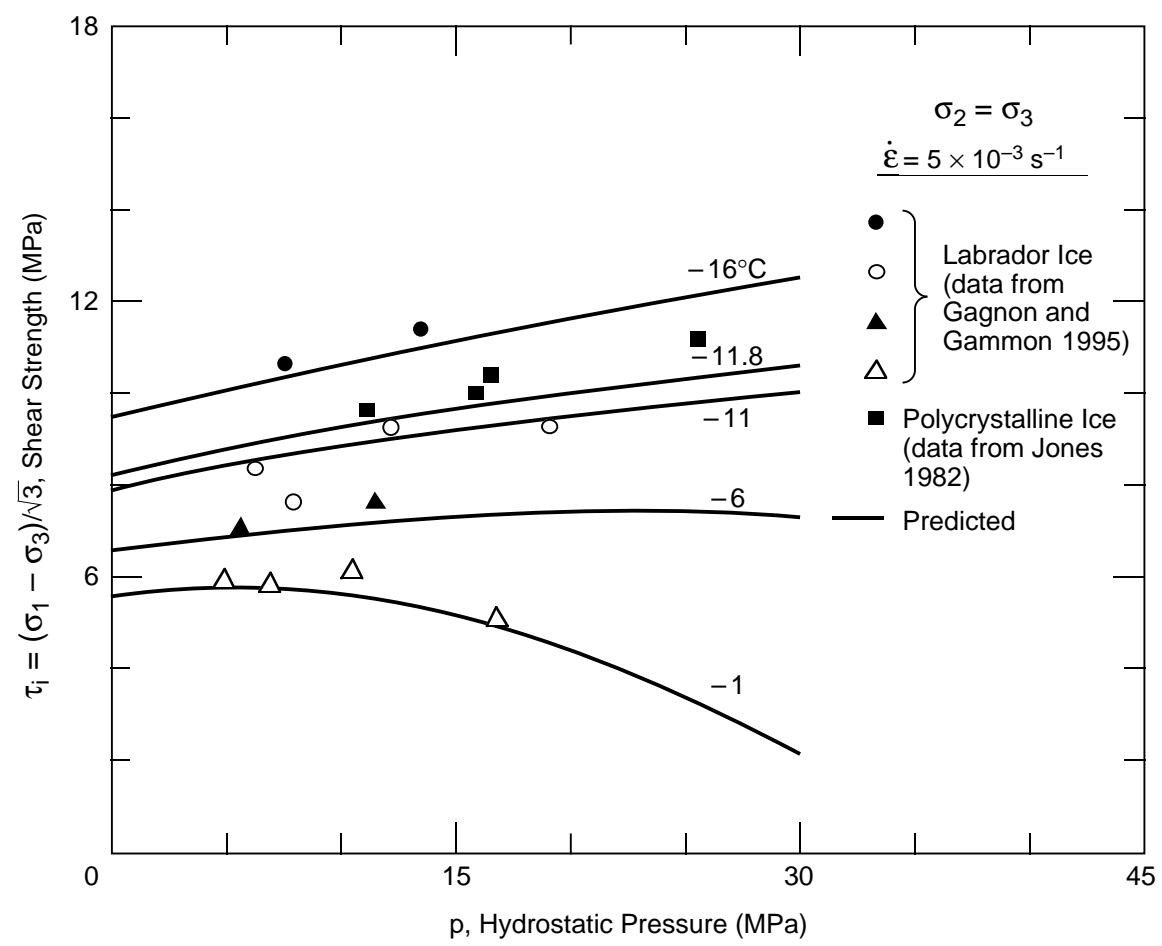

Figure 9. Predicted and test magnitudes of ice strength under triaxial compression at various temperatures. Data from Gagnon and Gammon (1995), and Jones (1982).

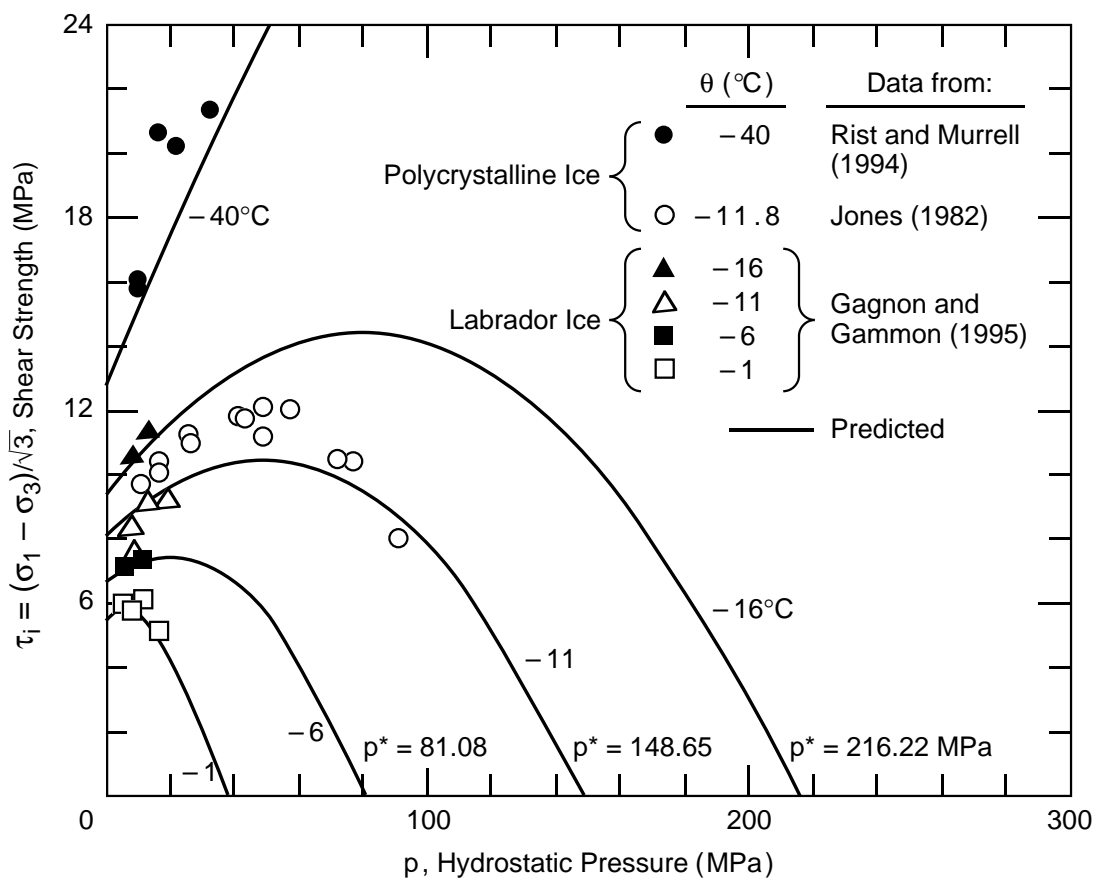

Figure 10. Strength of ice in the range of high hydrostatic pressures at $\dot{\varepsilon} \approx 5 \times 10^{-3} \mathrm{~s}^{-1}$. Data from Jones (1982), Gagnon and Gammon (1995), and Rist and Murrell (1994). 
eral trend of predicted values of ice strength as functions of the hydrostatic pressure is well confirmed by Jones' test data.

\section{SUMMARY AND CONCLUSIONS}

1. A temperature model has been developed that describes the ice strength in a multiaxial stress state over a wide spectrum of negative (subfreezing) temperatures.

2. The strength dependency of ice on the hydrostatic pressure and temperature is well described by eq $5 a$, which is a parabolic yield criterion:

$$
\tau_{\text {io }}(p, T)=(c+b p)-\left(c+b p^{*}\right)\left(\frac{p}{p^{*}}\right)^{2}
$$

with only three fundamental physically wellfounded parameters: the ice cohesion $c(T)$, angle of internal friction $\phi(T)$ or $b(T)$, and ice melting pressure $p^{*}(T)$. They all have a definite physical meaning and are functions of temperature.

3 . The temperature model was developed based upon data on over 100 triaxial compression tests of iceberg ice and laboratory-made freshwater randomly oriented polycrystalline ice with a grain diameter between $\sim 1 \mathrm{~mm}$ and $\sim 8 \mathrm{~mm}$ in the temperature range between $-1^{\circ}$ and $-40^{\circ} \mathrm{C}$ at the range of strain rates between $10^{-3} \mathrm{~s}^{-1}$ and $10^{-5} \mathrm{~s}^{-1}$.

4 . Further studies are required of the temperature dependencies of the ice strength parameters for various types of ice, particularly the ice melting pressure over a wider spectrum of temperatures, strain rates, and confining pressures.

\section{LITERATURE CITED}

Barnes, P.D., F.R.S. Tabor, and J.C.F. Walker (1971) The friction and creep of polycrystalline ice. Proceedings, Royal Society of London, Ser. A. 347: 493-512.

Casassa, C., H. Narita, and N. Maeno (1991) Shear cell experiments of snow and ice friction. Journal of Applied Physics, 69(6): 3745-3756.

Drucker, D.C., and W. Prager (1952) Soil mechanics and plastic analysis of limit design. Quarterly Journal of Applied Mechanics, 10: 157-165.

Fish, A.M. (1991) Creep and yield model of ice under combined stress. USA Cold Regions Research and Engineering Laboratory, Special Report 91-31.
Fish, A.M. (1992) Three-dimensional visco-plastic flow model of polycrystalline ice. In Proceedings, 3rd International Conference on Ice Technology, Massachusetts Institute of Technology, Cambridge, Massachusetts, 11-13 August (T.K.S. Murphy, W.M. Sackinger, and P. Wadhams, Eds.) Southampton, U.K.: Computational Mechanics Publ., p. 193-207.

Fish, A.M. (1993) Combined creep and yield model of ice under multiaxial stress. Journal of Offshore and Polar Engineering, 12(3): 130-139.

Gagnon, R.E., and P.H. Gammon (1995) Triaxial experiments on iceberg and glacier ice. Journal of Glaciology, 41(139): 538-540.

Hallam, S., and J.P. Nadreau (1988) Failure maps for ice. In Proceedings, 9th International Conference on Port and Ocean Engineering under Arctic Conditions (POAC '87) 17-22 August, Fairbanks, Alaska (W.M. Sackinger, and M.O. Jeffries, Eds.) Geophysical Institute of Alaska-Fairbanks, vol. 3, p. 45-55.

Hausler, F.U. (1983) Comparison between different yield functions for saline ice. Annals of Glaciology, 4: 105-109.

Jones, D.E., F.E. Kennedy, and E.M. Schulson (1991) The kinetic friction of saline ice against itself at low sliding velocities. Annals of Glaciology, 15: 242-246.

Jones, S.J. (1978) Triaxial testing of polycrystalline ice. In Proceedings, 3rd International Conference on Permafrost, Edmonton, Alberta, Canada. vol. 1, p. 670-674.

Jones, S.J. (1982) The confined compressive strength of polycrystalline ice. Journal of Glaciology, 28(98): 171-177.

Jones, S.J., and H.A.M. Chew (1983) Creep of ice as a function of hydrostatic pressure. Journal of Physical Chemistry, 87(21): 4064-4066.

Nadreau, J.P., and B. Michel (1986) Yield and failure envelope for ice under multiaxial compressive stresses. Cold Regions Science and Technology, 12(1): 75-82.

Nadreau, J.P., A.M. Nawwar, and Y.S. Wang (1991) Triaxial testing of freshwater ice at low confining pressures. Transactions of ASME, 113: 260-265.

Reinicke, K.M., and T.D. Ralston (1977) Plastic limit analysis with an anisotropic, parabolic yield function. International Journal of Rock Mechanics and Mining Sciences, 14(3): 147-154.

Richter-Menge, J.A., G.F.N. Cox, N. Perron, G. Durell, and H.W. Bosworth (1986) Triaxial testing of first-year sea ice. USA Cold Regions Research and Engineering Laboratory, CRREL Report 86-16. 
Rist, M.A., and S.A.F. Murrell (1994) Ice triaxial deformation and fracture. Journal of Glaciology, 40(135): 305-318.

Sayles, F.H. (1974) Triaxial constant strain rate tests and triaxial creep tests on frozen Ottawa sand. USA Cold Regions Research and Engineering Laboratory, Technical Report 23.

Smith, M.B. (1974) A parabolic yield condition for anisotropic rocks and soils. Ph.D. thesis, Rice University, Houston, Texas.

Timco, G.W., and R.M.W. Frederking (1986) Confined compression tests: Outlining the failure envelope of columnar sea ice. Cold Regions Science and Technology, 12: 13-28.
Weiss, J., and E.M. Schulson (1995) The failure of freshwater granular ice under compressive loading. Acta Metallurgica Material, 43(6): 23032315.

Zaretsky, Yu.K., and A.M. Fish (1996a) Model of viscoplastic deformation of frozen and unfrozen soils and ice. In Proceedings, 6th International Offshore and Polar Engineering Conference, 26-31 May 1996, Los Angeles, vol. 2, p. 291-296.

Zaretsky, Yu.K., and A.M. Fish (1996b) Effect of temperature on the strength and viscosity of ice. Journal of Soil Mechanics and Foundation Engineering (translated from Russian), vol. 33(2): $46-52$. 
Public reporting burden for this collection of information is estimated to average 1 hour per response, including the time for reviewing instructions, searching existing data sources, gathering and maintaining the data needed, and completing and reviewing the collection of information. Send comments regarding this burden estimate or any other aspect of this collection of information, including suggestion for reducing this burden, to Washington Headquarters Services, Directorate for Information Operations and Reports, 1215 Jefferson Davis Highway, Suite 1204 , Arlington, VA 22202-4302, and to the Office of Management and Budget, Paperwork Reduction Project (0704-0188), Washington, DC 20503.

\begin{tabular}{|l|l|l}
\hline 1. AGENCY USE ONLY (Leave blank) & 2. REPORT DATE & 3. REPORT TYPE AND DATES COVERED
\end{tabular}

4. TITLE AND SUBTITLE

October 1997

Ice Strength as a Function of Hydrostatic Pressure and Temperature 6. AUTHORS

Anatoly M. Fish and Yuri K. Zaretsky

7. PERFORMING ORGANIZATION NAME(S) AND ADDRESS(ES)

U.S. Army Cold Regions Research and Engineering Laboratory

72 Lyme Road

Hanover, New Hampshire 03755-1290

9. SPONSORING/MONITORING AGENCY NAME(S) AND ADDRESS(ES)

Office of the Chief of Engineers

Washington, D.C. 20314-1000

8. PERFORMING ORGANIZATION

REPORT NUMBER

CRREL Report 97-6

PE: 6.27.84A

PR: 4A762784AT42

WP: 201

WU: CA-D13

Washington, D.C. $20314-1000$

11. SUPPLEMENTARY NOTES

For conversion of SI units to non-SI units of measurement, consult ASTM Standard E380-93, Standard Practice for Use of the International System of Units, published by the American Society for Testing and Materials, 1916 Race St., Philadelphia, Pa. 19103.

12a. DISTRIBUTION/AVAILABILITY STATEMENT

12b. DISTRIBUTION CODE

Approved for public release; distribution is unlimited.

Available from NTIS, Springfield, Virginia 22161

13. ABSTRACT (Maximum 200 words)

A temperature model has been developed that describes the ice strength in a multiaxial stress state over a wide spectrum of negative temperatures. The model takes into account the anomalous behavior of ice under high hydrostatic pressure, when its strength reaches a maximum, and then gradually decreases with the pressure increase. It has been shown that strength of ice under high hydrostatic pressure is described by a parabolic yield criterion with only three fundamental parameters, ice cohesion, internal friction angle, and ice melting pressure, which all have a definite physical meaning and are functions of temperature. The model has been verified using test data on the strength of iceberg ice and laboratory-made polycrystalline freshwater ice under triaxial compression at strain rates between $10^{-3}$ and $10^{-5} \mathrm{~s}^{-1}$ over the temperature range between $-1^{\circ}$ and $-40^{\circ} \mathrm{C}$.

\begin{tabular}{|c|c|c|}
\hline \multicolumn{3}{|l|}{ 14. SUBJECT TERMS } \\
\hline Freshwater ice & \multicolumn{2}{|l|}{ Temperature model } \\
\hline Ice melting pressure & \multicolumn{2}{|c|}{ Triaxial compression tests } \\
\hline $\begin{array}{l}\text { 17. SECURITY CLASSIFICATION } \\
\text { OF REPORT }\end{array}$ & $\begin{array}{l}\text { 18. SECURITY CLASSIFICATION } \\
\text { OF THIS PAGE }\end{array}$ & $\begin{array}{l}\text { 19. SECURITY CLASSIFICATION } \\
\text { OF ABSTRACT }\end{array}$ \\
\hline UNCLASSIFIED & UNCLASSIFIED & UNCLASSIFIED \\
\hline
\end{tabular}

